\title{
From new space to big space: How commercial space dream is becoming a reality ${ }^{\text {is }}$
}

\author{
Gil Denis ${ }^{\mathrm{a}, *}$, Didier Alary ${ }^{\mathrm{a}}$, Xavier Pasco ${ }^{\mathrm{b}}$, Nathalie Pisot $^{\mathrm{a}}$, Delphine Texier ${ }^{\mathrm{a}}$, Sandrine Toulza $^{\mathrm{a}}$ \\ ${ }^{\text {a }}$ Airbus Defence and Space, 31 rue des cosmonautes 31402 Toulouse, France \\ ${ }^{\mathrm{b}}$ Fondation pour la Recherche Stratégique, 4 bis rue des pâtures 75016 Paris, France
}

\section{A R T I C L E I N F O}

\section{Keywords:}

Newspace

Innovation

Space economy

Space ecosystem

Start-ups

Venture capital

\begin{abstract}
A B S T R A C T
New space is a misleading expression. Many new trends steer the evolution of space activities. Development of commercial space, with start-ups and space ventures, is one of the most visible trends in space. Stimulated by the first initiatives related to space tourism, access to space and the growing use of small satellites, space activities have attracted new entrepreneurs, both start-ups and big web actors with substantial investment capacity. This revolution started in the Silicon Valley and spread worldwide. Start-ups have attracted around \$21.8 billion of investment from 2000 to 2018 . It is far below the annual institutional budgets but the pace gained momentum since 2006 and specially 2012 .

Between teenage crisis and age of reason, New space is now old: the first start-ups shall confirm their promises, while new players pop up and try to find their way. It shakes the legacy players but they demonstrate resilience and adaptation capacity. It is now the right time to take stock of the first lessons learnt. Start-ups disrupt the established industry? Instead of a simplistic shortcut, this paper reports an "organizational ecology" study. With a deliberate industrial viewpoint, its ambition is to help understanding complex evolutions in the space ecosystem.

The first part of the paper introduces the current ecosystem, its actors, the key trends and the main types of activities. Through facts and figures on technology, investments and markets, the second part reviews how "new space" trends are preparing the advent of big space. The third part summarises lessons from other industries and typical disruption scenarios that could affect space activities. The drivers of New space are discussed in section four. The last part is a foresight exercise, discussing possible evolutions and impacts, threats and opportunities. The decisive role of institutional actors and the « new space » with more and more space-faring nations is also highlighted.

Something big is happening in space. While it is too early to depict the new landscape, this study shows that the future picture will not be black and white but more colourful. The size and the age of the company are less important than agility, mindset, ability to manage risks and to cooperate. A big vision for the future, from entrepreneurs or from nations, is also needed.
\end{abstract}

\section{An organizational ecology of new space}

\subsection{Taking stock of new space trends and impacts on industry}

This paper reports a first study on the evolution of the main, new or older, stakeholders of space activities in the context of New Space and growing weight of commercial space activities. The main objective is to provide an overview of new trends in space activities and an assessment of the impacts and possible evolutions of commercial space and its relation with institutional actors. Many papers address new space in a specific domain (Earth Observation, launchers, etc.). Without providing a new in-depth sectorial analysis, the original dimension of this study is to focus on interfaces and dependencies between the stakeholders of the space ecosystem. This is an "organizational ecology" study: who are the new entrants? How do they affect the existing companies and what is their impact on the market? How will

\footnotetext{
\Special thanks to François Auque, Nicolas Chamussy, Jean Dauphin, Pierre-François Delval, Arnaud de Rosnay, Serge Flamenbaum, Bruno Le Stradic, François

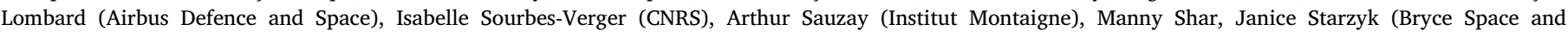
Technology).

* Corresponding author.

E-mail address: gil.denis@airbus.com (G. Denis).
} 


\author{
Acronyms and abbreviations \\ BAT Baidou Alibaba Tencent \\ B2B Business to business \\ B2C Business to consumer \\ B2G Business to government \\ COTS Commercial-off-the-shelf \\ EU European Union \\ GAFA Google Amazon Facebook Apple
}

GEO Geostationary Orbit

IADC Inter-Agency Space Debris Coordination

ICT Information and Communication Technologies

IOT Internet Of Things

ITU International Telecommunication Union

LEO Low Earth Orbit

M2M Machine to Machine

VC Venture Capital evolve policies and the role of institutional bodies?

The paper adopts a deliberate industry viewpoint and focus on commercial space activities as shown by the profile of the co-authors. Five of them work for Airbus Defence and Space, one of the major space primes, actively involved in commercial space. The sixth co-author, Dr. Xavier Pasco, is Director of the Foundation for Strategic Research (FRS) an independent think-tank based in Paris. He brings a complementary viewpoint, with considerations on nations, institutional actors (space and defence agencies) as key players of the ecosystems.

\subsection{New space? Many trends prepare big space}

Development of commercial space, start-ups and space ventures are some of the most visible trends in space in the $21^{\text {st }}$ century [1]. The pace gained momentum since 2006 and specially 2012. Stimulated by the first initiatives related to space tourism, access to space and the growing use of small satellites, space activities have attracted new entrepreneurs, both start-ups and big web actors with substantial investment capacity. This revolution started in the Silicon Valley and spread worldwide [2].

\subsection{Between teenage crisis and age of reason}

New Space is now getting older: Fig. 1 shows representative milestones. The first start-ups shall confirm their promises, while new players pop up and try to find their way. In the wake of SpaceX or Blue Origin, start-ups multiplied, with a wealth of new companies worldwide: what was once dominated by few players is today an incredibly diverse ecosystem in terms of company sizes, business models and geographic locations [3]. It is now the right time to take stock of the first lessons learnt. Start-ups disrupt established industry? Instead of a simplistic shortcut, the ambition of this study is to help understanding complex evolutions in the space ecosystem.

\section{New space: Darwinism in space}

\subsection{A challenge: defining new space}

\subsubsection{New space and old space}

New space is a misleading expression. It implies that there would be an old space, with old-fashioned or even musty habits. Many new trends steer the evolution of space activities. Finding a simple definition of New Space is not easy ... "New Space is that which is NOT old space". It's simple but not very useful. The Space Frontier Foundation, founded in 1988, defines New Space as "People, businesses and organizations working to open the space frontier to human settlement through economic development" [4]. Even if it offers an ambitious goal, this definition is probably too generic and with a too far horizon (at least with respect to usual business standards).

In the late 1990's new space began to be used in the United States to describe a new generation of space development, notably commercial. In Ref. [5], Martin Sweeting defines New Space as "the emergence of a different ethos for space where the established aerospace methods and business have been challenged by more entrepreneurial private sector by adopting more agile approaches and exploiting the latest commercial-off-theshelf technologies". He confirms that "it unfairly infers an old space". The wording was probably influenced by the spirit of the Silicon Valley and the book "The New New Thing: A silicon Valley Story" written by Michael Lewis [6]. But some people in the old Europe could argue that commercial Earth Observation was invented in France in 1982 by CNES when Spot Image was founded.

Other names have been used: Alt.space, originally meant as a new mindset and an "alternative way of doing things in space", entrepreneurial space or commercial space, funded by private investors. All definitions

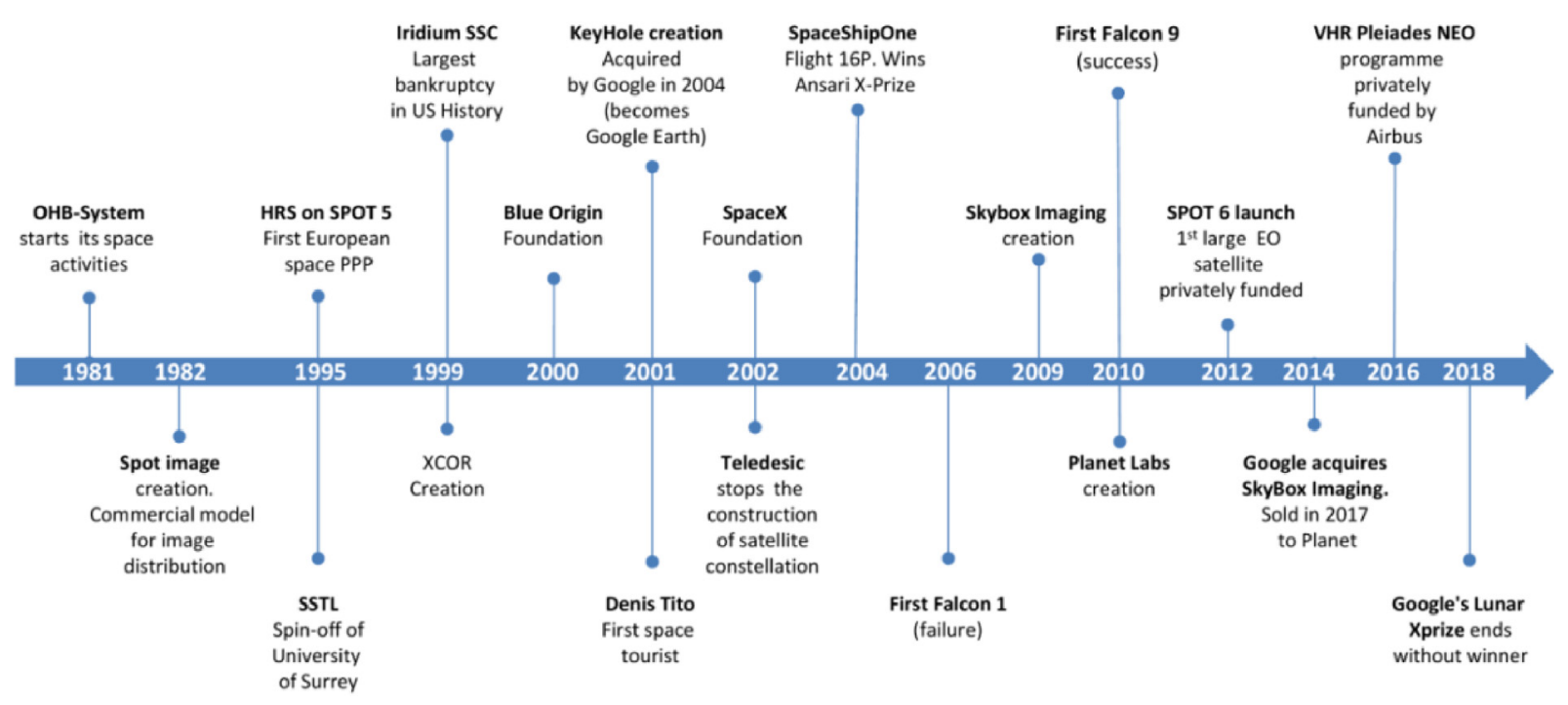

Fig. 1. Innovation in space - Some milestones. 
highlight the difference with standard space activities, although many industrial companies have private shareholders and address commercial markets. One common denominator is a lower or even the absence of involvement of government agencies, justified in rare cases by a pure libertarian capitalism ideology [7]. However, it is widely acknowledged that the public sector played a crucial role in the success of the first space ventures.

\subsubsection{New space: the disruptive dimension}

Still in the late 1990', the disruption or disruptive innovation concept is introduced in the theory of innovation by Jean-Marie Dru [8] and Clayton M. Christensen [9]. Disruptive innovation creates a new market and value network, and eventually disrupts the existing one, displacing or even destroying established market leaders. Disruptive innovations are often initiated by outsiders and entrepreneurs, rather than by existing market-leading companies. A disruptive process can be longer to develop and is more risky. However, once it is deployed, even with less performance at the beginning, it can have a very fast and strong impact on the established markets and players.

With the growing number of start-ups and space entrepreneurs, the words New Space and Disruption are often combined, sometimes with excessive expectations. For legacy players, disruptive innovation also happens when they are able to reinvent or adapt their own models. The use of Silicon Carbide or the Electric orbit raising are typical examples of successful innovation for Airbus Defence and Space.

\subsubsection{The attributes of new space}

More recently, there were some attempts to refine the definition of New Space by using specific attributes, in contrast with traditional way of working. A typical example is the work performed by the Tauri Group in 2009 [10]. An updated version of the main business attributes (non-exclusive) of the new and "old" space models is proposed in Ref. [11], showing that the main differentiators are not only the technology but also and mainly the business model and company "style": focus on services, pricing models, use of COTS and new approaches of reliability, incremental deployment ("walk before run"), revise methods inspired by DevOps culture, co-design with customer and suppliers, flat and agile organizations. Thus, the boundary between the two models is becoming increasingly blurred, with highly innovative programmes proposed by both large established companies and young start-ups. New entrepreneurs but also well-established corporations demonstrate their capacity to convince venture investors. The innovative character of the organization is not that much directly related to its age and its size but rather to its capacity to implement new ways of working and new ways of doing business.

A black and white picture with new space actors and old-fashioned companies is not relevant anymore, and this change is perhaps the most tangible impact of the boom of the space start-ups. While New space was understood a few years ago as a specific profile of new companies addressing space activities, it shall be considered now as a global trend affecting all players involved in the new space race.

\subsubsection{How many new spaces?}

There are many new things happening in space: new investors, new start-ups, new policies, new threats, new needs, new technologies, new value chains. All have impact on the space ecosystem. This diversity explains why it might be preferable using the terms «New trends in space » instead of « New Space » even if New Space remains convenient shorthand.

\subsection{Ecology applied to space activities}

\subsubsection{Introduction and rationale}

New Space is often considered as a stand-alone trend or as a revolution or disruption likely to replace past practices. The black and white vision hides a more complex reality, including also smooth evolutions and interactions between all actors involved in space activities. Bearing in mind the limits of this analogy, using an approach derived from ecology can be useful to depict more subtly the current evolutions affecting the space sector and the interactions between the various stakeholders. The rationale is based on the wording used when new space issues are discussed: competition, aliens, new ecosystems, etc.

\subsubsection{Ecology and ecosystems}

Ecology studies the interactions among organisms and their environment, including cooperation and competition [12]. In a nutshell, ecosystems can be studied as interdependent collections of living and non-living-components or as structured systems and communities governed by general rules. The components interact through nutrient cycles and energy flows. Ecosystems include interactions among organisms, and between organisms and their environment. The energy used by ecosystems comes primarily from the sun via photosynthesis.

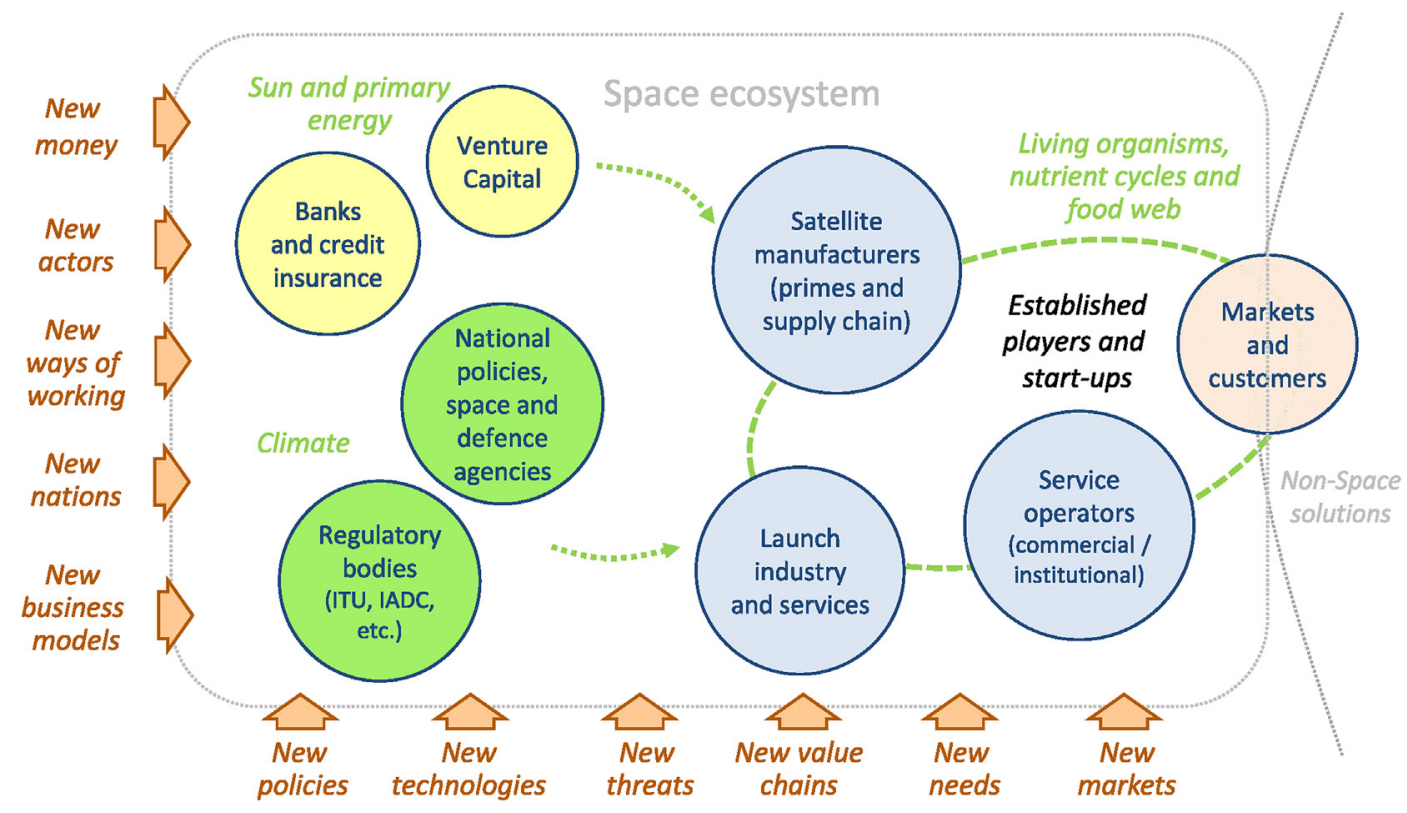

Fig. 2. Darwinism in space, our model of the space ecosystem and new trends influencing its evolutions. 
Ecosystems are controlled by both external (e.g. climate) and internal factors. Ecosystems are dynamic and subject to disturbances.

\subsubsection{Invasive species and aliens}

The introduction of non-native species can cause substantial shifts in ecosystem function. An invasive species [13] or aliens is a species that is not native to a specific location and can cause damage to the ecosystem. Invasive species may drive local native species to extinction via competitive exclusion, niche displacement, or "introgression", i.e. hybridisation with related native species.

\subsubsection{A simplified model of space ecosystem}

The work reported in this paper is built along the model depicted on Fig. 2 with two components: the network of stakeholders involved in space activities and a list of new trends, evolution or disturbances that can impact the ecosystem. Furthermore, space activities shall not be seen as isolated from a global ecosystem with other solutions (e.g. ground communications).

\subsection{The new space zoo: usual suspects and aliens}

Based on this model, the New space zoo encompasses five main components: 1) the market and the customers, 2) the space industry, including the primes and the supply chain, with both established companies and start-ups (in blue on Fig. 2), the main focus of this paper, 3) the service operators, 4) the financing sources and 5) the nations (space and defence agencies) and the international bodies (e.g. ITU, IADC). Many trends or « New things » happening affect their evolution and behaviour (orange arrow on Fig. 2).

\subsubsection{The markets and the customers}

With the exception of the space communications market, space activities are usually related to public-sector customers or governmental activities with rather long-term projects. The main assumption of New space is that there is an untapped potential in commercial space activities [14]. The so-called «Democratization of space» implies that commercial interests play a leading role or at least that resources of governments and commercial enterprises shall be combined for better efficiency. Main drivers of the new appetite for space activities are the new needs: global connectivity, digital transformation of the society, IOT and M2M, etc. Other markets, including ISRU (In Situ Resource Utilization) are fully new with longer term return on investment and large uncertainties on market size and accessibility.

\subsubsection{Satellites operators}

In the telecommunications sector, an important trend is the emergence of several massive constellations projects in Low Earth Orbit providing global Internet connectivity worldwide: Oneweb, Starlink, Leosat etc. A second trend is the development of services based on small GEO platforms, not only for commercial customers but also for military application (resilience). A last trend is the new services based on Delay Tolerant Networks for M2M and IOT applications: A study prepared by Research and Markets forecasts 100 billion connected devices in 2025 [15].

In Earth observation, the new space trend, also based on LEO constellations, is to provide higher revisit or even permanent video from space. This is the main differentiator with respect to the providers of very high resolution imagery. A second move is the development of image analytics services, addressing new markets (e.g. finance, insurance, etc.)

\subsubsection{Launchers and satellite industry}

The main novelty is the increasing number of new private actors trying to disrupt the current supply chain with new approaches: smaller satellites, new orbits, use of COTS, etc. They propose also new business models or commercial approaches, including more vertically integrated supply chains and integration of the service offer. There are two main profiles. More and more start-ups, backed by private ventures funds, develop very small satellites or constellations of small satellites for operational missions. The big players of the Web sphere (GAFA and BAT) are increasingly interested by Space and able to invest massively, either directly or through new companies. Regarding the launchers, the new space trend is making access to space more affordable. Elon Musk with SpaceX and the success of its Falcon 9 with reusable first stages is undoubtedly the main iconic symbol of entrepreneurial space.

\subsubsection{Finance sources}

The most significant change is the growing role of private investors and venture capital in the space industry. New investors in space have various profiles and the investment objectives are very different if made by business angels, venture capitalists, major industrial groups (corporate ventures), young Internet billionaires or space enthusiasts. Business angels are more inclined to support the space activity of a start-up on the mid to long-term while venture capitalists seek rapid financial results (e.g. exit opportunities).

Led by Masayoshi Son, the giant Japanese conglomerate Softbank and its Vision Fund, the world's largest technology fund, is a very specific case: it invested $\$ 1.5 \mathrm{~B}$ in OneWeb, becoming largest shareholder. The importance of credit insurance in export contracts might also be mentioned.

\subsubsection{Big space: worldwide, no frontiers and no flags? The role of nations,} space and defence agencies

There are tight links between New space and the national space policies. New space finds its roots in the United States in the nineties. The issue then was to help a massive American military-industrial complex to turn into an economic and political asset in the context of the post-Cold War era. The federal state decided to structure a new private space sector and support its development, with commercial and business incentives (becoming its first client) and by regulation.

The joint development of this new sector with the booming information and communication technologies (ICT) sector (also supported by the US government) created optimal conditions for the dawn and viability of New Space in the 2000s.

An unprecedented effort to outsource transportation systems to the space station has deeply transformed the relationship between the space agency and its industrial base. The industrial activity was supported through an accelerated privatization of a part of the manned space flight along with a wider distribution of federal funds via the Commercial Orbital Transportation Services and the Crew development programmes initiated in 2006 and 2009. New space actors such as Space X or Sierra Nevada emerged, while NASA had to refocus on deep space exploration. Several other private actors (Blue origin, Virgin Galactic) joined the race with their own objectives (e.g. space tourism).

Is New space specifically a US trend? Local importance of space activities, appetite for innovative ventures and risk culture: no other spacefaring nation has experienced such a convergence of favourable developments. Even if the development of New space and start-ups started later and remains relatively low compared to what happened in the US, the New space phenomenon is now affecting other space faring nations.

In Europe, the European Space Agency (ESA) was historically built to design and manage scientific space programs. The advent of a new industrial competition in the US has prompted ESA member States to reorganize the European landscape, with a greater responsibility given to industry (leading to the creation of Ariane Group). The European Union (EU) has also engaged in an ambitious space policy. Focusing on space applications, the EU owns today two major systems, namely Galileo, the European navigation program, and Copernicus, a constellation of optical and radar satellites aimed at providing information for environmental monitoring. Initially aimed at supporting public policies, the EU space programs target now the economic development 
and the private sector. Other space champions (China, India, etc.) have new ambitions on the commercial and export markets. The size of their internal market is a huge asset. In 2018, China performed 39 orbital launches.

Several private ventures have been regularly reported in China even if in limited numbers and with a strong link with Chinese government. Beside the main spacefaring nations, more and more nations become active players in space activities and this trend is sometimes triggered by private companies (e.g. New Zealand became a space fairing nation, able to launch orbital rockets, because Rocket Lab performed the first successful flight of its new small launcher (Electron).

\subsection{A taxonomy of an evolving ecosystem}

Our breakdown of space activities has five main categories (> Fig. 3): this segmentation is derived from the one used by Northern Sky Research [2] but we consider that their three categories are too broad and mix markets accessible in the short-mid-term with more speculative initiatives with long term payoffs.

\subsubsection{Going to space...}

Reducing launch costs and making access to space easy and affordable is definitely one of the most visible efforts undertaken by new space actors. Orbital launchers are also one of the best examples illustrating the national dimension with a traditional space ecosystem involving space agencies and large companies, often related to military activities (ballistic missiles and nuclear deterrence).

After the last launch of Space Shuttle in July 2011, the USA became dependent on Russian Soyuz spacecrafts for the rides of American astronauts to the ISS. This strong symbol stimulated the ongoing efforts to develop new and more competitive launchers, with three important streams. The most spectacular one is the success of SpaceX: Falcon 9 is today the world's most widely used rocket. Furthermore, SpaceX became the first company to orbit a spacecraft with a reused rocket. SpaceX has disrupted the existing duopoly (Arianespace and United Launch Alliance).

The second trend is the growing interest for suborbital flights and space tourism. Even if the business case is not yet proven, the efforts spent on this activity had direct impacts on the orbital launchers. Starting with a suborbital rocket (New Shepard), Jeff Bezos and BlueOrigin publicly released the general design of the orbital launcher New Glenn in September 2016. Working in a more silent mode compared to SpaceX, Jeff Bezos had been investing in Blue Origin for 18 years and signed contracts with Eutelsat, OneWeb, SkyPerfect Jsat and Mu Space.

The third noticeable stream is the active quest for small launchers for small satellites. There are many initiatives and the first successful result occurred in January 2018: during its second flight, Rocket Lab's Electron rocket reached orbit and deployed three cubesats. Rocket Lab is not the only one: Vector Space Systems launched a full-scale prototype of its Vector-R launch vehicle in late 2017, while Virgin Orbit is working toward $300-500 \mathrm{~kg}$ payloads with its Boeing 747-based inflight launch system. The evolution of access to space with affordable and available launch options is obviously a strong enabler of all space activities.

\subsubsection{Down to Earth}

This sector is particularly meaningful because it includes both institutional and commercial markets, with market growth opportunities and tougher competition.

For Earth observation, satellites were owned until recently by governmental organizations or by commercial operators contracted by public institutions, through public investment or PPP: the public sector is the main user with more than $75 \%$ of commercial imagery purchased by public institutions. Around 2009, a major change was the emergence of new players, exclusively funded by private money. Skybox or Planet
Labs (now Planet) are two typical examples but there is a wealth of initiatives. Their disruptive approach is based on (1) missions focusing on revisit, while existing operators propose very high resolution (Fig. 4), and (2) the ambition to provide data at a very-low price, thanks to the development of a low-cost infrastructure. Their ambition is to develop new usages and new types of customers, thus increasing the size of the market. While the evolution of the EO data market is still limited, three structuring impacts are visible: 1) low-cost approach is a game-changer in satellite manufacturing, 2) revisit matters more and is highly considered for replacement of legacy missions and 3) the investment in data analytics and artificial intelligence is booming. The meteorology and climate monitoring missions are, "par excellence" operated by public agencies but some start-ups see market opportunities. New trends in Earth observation are described in details in Ref. [19].

Communication satellites and services are already the main commercial part of the space industry. While the market is largely dominated by operators of GEO satellites ( $\$ 115 \mathrm{~B}$ in 2017), the disruption comes from large constellations initiatives with dozens, hundreds or even thousands of satellites in LEO orbits. Driven by broadband global connectivity, their main selling point is low latency. The new players are not only young start-ups: O3B, Oneweb, Starlink, Boeing, Viasat, Telesat, Leosat are backed by GAFA and very large investors (Softbank) and rely on a solid industrial basis. These complex systems require a large CAPEX investment and the main risks are related to the actual size of the market, the competition against terrestrial solutions, the regulatory issues (e.g. frequency management) and the deployment ramp up. New space start-ups address also new markets such as IOT and M2M, where less complex and more affordable systems are relevant.

\subsubsection{Space for space}

This segment covers all activities related to operations in space, with diverse maturity levels: debris mitigation and end of life disposal, in-orbit servicing (IOS), including refuelling, repairing, upgrading and space tugs services, in-space manufacturing. It covers also debris mitigation and post-mission disposal. This market is rather young and its value is uncertain.

The rationale is the direct consequence of the space democratization, the increasing number of small satellites and the emergence of massive constellations. According to a report on the Emerging Space Market Opportunity [2], 74 companies have been founded in this segment between 2000 and 2016. The total investment is $\$ 1.2$ Billion.

The majority of demand for In-Orbit services comes from commercial GEO satellite operators. The emerging legal framework raises issues regarding liability for future damages resulting from these missions. Relevant examples of initiatives are Orbital ATK's MEV (Mission Extension Vehicle), Effective Space Solutions' space drones and Airbus Defence and Space O.CUBED Services.

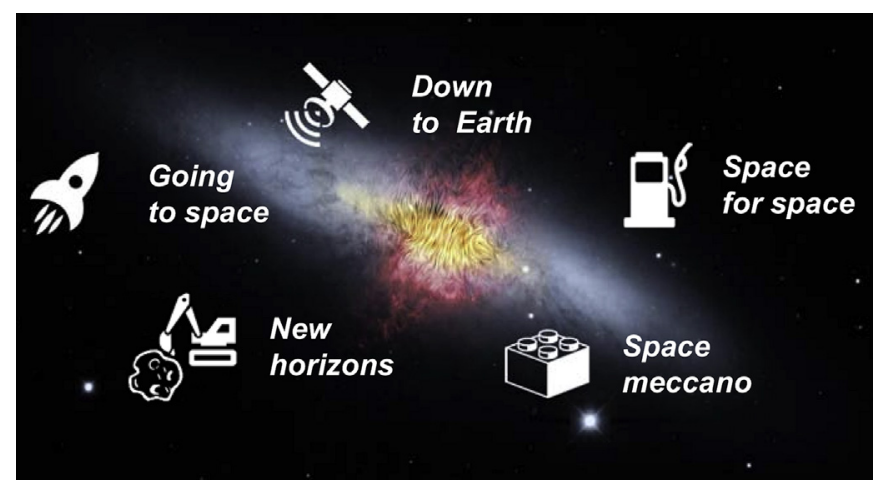

Fig. 3. A space taxonomy with five categories. 


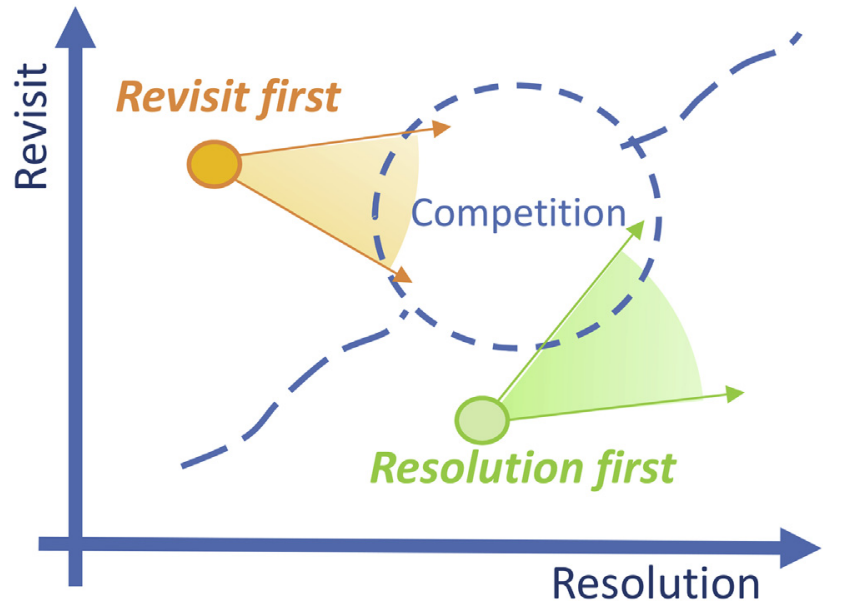

Fig. 4. Resolution and/or revisit, the new battle between the newcomers and the incumbent actors.

\subsubsection{New horizons ... space far from Earth}

Moon, Mars, asteroids ... This segment covers disruptive approaches for very long term applications such as asteroid mining (In Situ Resource Utilization: ISRU), exploration or journey to Mars. ISRU concepts were initially designed by space agencies and scientific institutions. Some start-ups raised significant amounts of money. Their rationale is the scarcity of precious metals like platinum, palladium and rhodium that can be found on NEOs (Near-Earth Objects). The potential market for commercial activities is rather uncertain with issues related to the Outer Space Treaty [16] and its guidelines regarding activities on celestial bodies [17]. After the United States, Luxembourg became the first European nation to adopt a legal and regulatory framework recognizing that space resources can be owned by private companies. Regarding Moon exploration, the Lunar Xprize with an initial deadline in 2014, ended in March 2018 with no winners. Meanwhile, SpaceX and Amazon are working on human landings on Moon and Mars.

\subsubsection{The "space Meccano »: components for space}

The space supply chain usually organised in "tiers". Smallsats platforms, electric propulsion engines, flat antennas, optical communication terminals, software defined radio modules, generic mission control or telemetry, etc.: the boom of the cubesats and smallsats fostered the emergence of new companies in the space supply chain and the evolution of the legacy ones. They provide subsystems, equipment and components. There are four main trends.

1) Miniaturization and standardization: the most representative example is the development of cubesats with COTS components warehouses and online stores.

2) The emergence of new specialised suppliers, targeting cost reduction through mass production. A typical example is electric propulsion for small satellites (e.g. Thrust Me) or software-defined radio modules for communications payloads (e.g. Cesium Astro).

3) Vertical integration, ensuring control of the supply chain (e.g. SpaceX) and, sometimes, bypassing heavy contracting and procurement processes. A full integration is the merging between service operation and satellite manufacturing (e.g. Planet with the Dove satellites or Maxar with Digital Globe).

4) New manufacturing techniques such as additive manufacturing (e.g. Rutherford engine of Electron rocket).

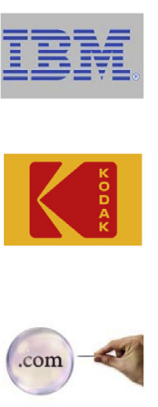

Reinvention
through
services

T99819 Too big to

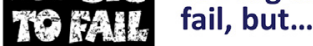

\section{The blind innovator

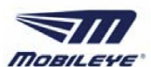 \\ Turmoil in the value chain}

Fig. 5. Six disruptive scenarios. Are they applicable to space industry?

\section{Disruption in space? Lessons from other industries and typical scenarios}

\subsection{Overview}

Past disruptions in other industrial sectors have affected the existing landscape. How far can they can be applied to the space ecosystem. How can they prefigure what will happen in the coming years? Six "extreme" scenarios (Fig. 5), not necessarily exclusive are useful to evaluate possible evolutions of the space markets and interactions between the stakeholders.

\subsection{Scenario "IBM": the successful reinvention or the services revolution}

IBM' successful strategic moves are numerous. One of the most famous one occurred a few years after IBM invented the PC in 1981. Lowcost clones quickly started to develop and capture large market shares. In 1991, IBM reported its first operational losses and thus decided a new ambition: "become a world-class services company". The success of this strategy shows that large companies can implement disruptive innovation and reinvent themselves.

\subsection{Scenario "Eastman Kodak": the blind champion, unable to see business} revolution

How a market leader fields for bankruptcy ... Kodak completely missed the rise of digital technologies, although the first digital camera was invented in 1975 by Steve Sasson, an engineer working for Kodak. In fact, Kodak was not blind: the company saw the disruptive potential. But the size of the legacy film activity and the limited competition prevented them to understand that a technology outside Kodak's core business would quickly disrupt them. The irony is that legacy players, with their access to market, experience, talents and investment capacity are often in the best position to seize new opportunities.

\subsection{Scenario "bubble dot com": new champions behind the smokescreen}

The dot-com bubble or Internet bubble occurred from 1995 to 2000 with excessive speculation triggered by the huge growth of Internet usage. The "growth over profits" strategy and the massive amount of capital available fuelled speculation in ICT. The burst of the bubble lasted from 2000 to 2002. Many dot.com companies failed completely and disappeared. Other companies suffered but survived and became the new champions: Amazon (founded in 1994), Google (1998), Cisco (1984), Qualcomm (1985) or Tencent (1998), Alibaba (1999) and Baidu (2000) in China. Once the dust has settled, a new landscape appeared.

\subsection{Scenario "too big to fail, but ..."}

"Too big to fail" is a concept whereby a business has become so essential to the global economy that a government will provide 
assistance to prevent its failure. But sometimes, big is not big enough. The most well-known example is Lehman Brothers investment bank. In 2008, US government said no to its bailout. Lehman Brothers filed for bankruptcy and this event triggered a financial tsunami with cascading effects. Too big to fail refers mainly to banks and financial operators but there are some examples in the industry: in 2009, General Motors and Chrysler both filed for Chapter 11 bankruptcy and only one survived thanks to a the government bailout.

3.6. Scenario "turmoil in the value chain": from cars ownership to mobility services

Electric cars (Tesla), autonomous vehicles (Waymo), per-mile pricing, car sharing (Blabla car) or cab rides (Uber or Lyft) services and platforms, software and digitization, end of car ownership. Whether driven by new technologies or business innovation, many trends shake car industry [18]. Until now, carmakers stand on top of the value and supply chains but it could change. Powerful start-ups like Uber propose new paradigms and force established players to reinvent their strategy and their business case, pushing them to develop expertise in areas outside their core skills, if they want to maintain their leadership. There are also huge changes in the supply chain with new technologies (batteries, communication, sensors, AI-based software). Some suppliers, in charge of critical functions, could improve their position in the value chain. Cars could thus become a commodity with a new distribution of the added-value between the providers of mobility services, the car manufacturers and the suppliers. One can also foresee a more important role of companies in charge of the road infrastructures.

\subsection{Scenario "la vie en rose" or start-ups paradise?}

What happens if the bubble inflates, slowly but without bursting? Beyond the buzz and often excessive expectations, a key condition is a large market growth confirming the foresight and the enthusiasm of venture capital investors. GAFA (Google, Apple, Facebook, Amazon) and BAT (Baidu, Alibaba and Tencent) emerged after the first dot-com crisis. The new Internet revolution fosters new opportunities: with the rising operational use of artificial intelligence, the digital transformation is starting to affect not only the consumers but all economic sectors with disruption of many industries. Education, health, human resources, legal, bank and finance, etc.: a wealth of start-ups are created every day, hoping to disrupt the legacy players.

\section{From new space to big space: what are the drivers?}

\subsection{The technology behind big space}

\subsubsection{Small is beautiful}

The technical trend is clear: thanks to electronics miniaturization, a function is now half or one-third of the mass and power needed ten years ago. The first option to exploit this shrink is to reduce the size/ mass and therefore the cost and the launch cost of a satellite. It is not only true for cubesats but also for medium and large-size satellites, while showing similar or better performances.

The second option augments the performance at a given mass. Geostationary satellites are a typical example, with around the same mass, but throughputs improved by orders of magnitude.

\subsubsection{How small is small: towards new sweet spots}

Several studies [5] have similar conclusions: there is a sweet spot for operational missions, between 30 and $220 \mathrm{~kg}$ wet mass, with two subclasses of $30-80$ and $80-220 \mathrm{~kg}$. The lower one is above the standard cubesat range. A typical platform is the SSTL 42 (Fig. 6). The upper one is already well known with many platforms such as Myriade (CNES), SSTL 100 or Proba. OneWeb constellation is using spacecrafts around $150 \mathrm{~kg}$, exactly in this upper sweet spot. Nevertheless, the laws of physics (diffraction, power dissipation, etc.) still apply: missions such as very high resolution observation need large aperture instruments [19] and are not compatible with very small platforms.

\subsubsection{A revolution in orbit: the rise of constellations}

Designing an operational constellation with hundreds of very small satellites is now possible. Therefore, constellations offering continuous coverage (with tens to thousands LEO satellites depending on their coverage) are now accessible to start-ups or new ventures, if they are able to convinced wealthy investors. The burst of massive constellations (above 100 satellites) is very new. Constellations have obvious technical advantages (lower latency, global coverage) but are complex systems. There are many challenges at design, manufacturing, launch and operations levels: mass production, "pack" launch with dispensers, maximized autonomy for simpler operation, redundancy at system level with hot spares post-mission disposal, new production lines and new testing strategies, etc.

\subsubsection{When small things build a large system}

Telecom or navigation constellations in LEO or MEO have a total mass from 20 to 100 tons of hardware in space (O3B, Globalstar,

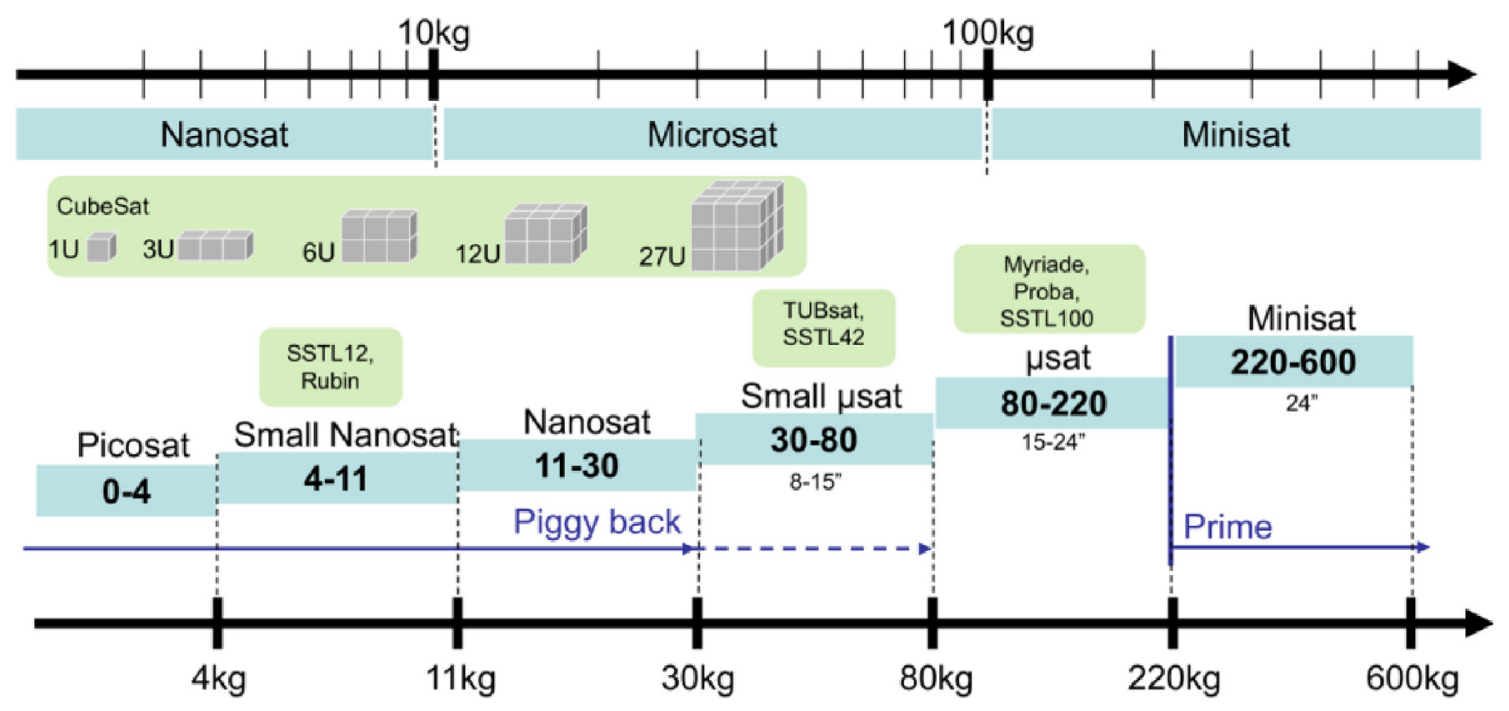

Fig. 6. Evolution of satellite mass and emergence of new sweet spots. 
Iridium, GPS, Galileo, OneWeb). Some companies announce constellations with above 1000 tons in orbit. Those numbers are disruptive when compared with the current 350-400 tons put each year in orbit.

Such architectures are complex. Can a large constellation be developed by a start-up working in "garage mode"? The Earth observation constellations are on the other side of the rule. Most of the new players want to deliver an operational sustainable service with 0.5 ton of hardware in orbit (e.g. 100 cubesats of $5 \mathrm{~kg}$ each), where established companies (Digital Globe, Airbus Defence and Space) have each ten times this mass in orbit. Obviously, this is a challenge in both cases.

\subsection{5. " Failure is not an option », still true?}

Since decades, the mass is a fundamental driver of the cost of a satellite, and still is. But the quality of the components is the other main factor. As long as access to space is expensive, developing a spacecraft remains a zero risk process, thus calling for ad hoc redundancies. For constellations with hundreds of satellites, redundancy can be considered at system level, and each satellite can be less reliable that a classical one. The use of off the shelf components (COTS) is much cheaper than space grade components. In addition, those components usually have lower constraints with respect to export control and their procurement is easier.

\subsection{Big space? Money talks: facts and figures}

\subsubsection{Space boom or "badaboum"?}

Big space is driven by the digital transformation, triggering new services, new markets and new customers: connectivity, Big Data, mobility and Earth observation. Morgan Stanley Research [20] expects worldwide space segment revenue to grow into $\$ 1100 \mathrm{~B}$ by 2040 , while admitting a "significant execution risk". In a report released in October 2017 [14], Bank of America Merril Lynch is even more optimistic: the space market is expected to grow to US $\$ 2.700 \mathrm{~B}$ by 2045: "for those wishing to take a truly long term time horizon we see it as one of the final frontiers of investing" with some "moon shots" initiatives.

\subsubsection{Space activities worldwide}

Where does the money flow in this new gold rush? According to a study performed by Bryce for the Satellite Industry Association [21], the global space industry is estimated to be worth $\$ 360 \mathrm{~B}$ in 2018, 77\% being generated by the commercial market. The breakdown is depicted on Fig. 7.

Manufacturing of satellites represents only $7 \%$ of the space industry revenues. The commercial part of the space industry is dominated by the satellites services, the largest segment, such as the Television Broadcast and Fixed Satellite Services. The growth is stable $(\sim 3 \%$ per year and 20\% over 2013-2018).

\subsubsection{National budgets}

The national budgets represent roughly $\$ 80 \mathrm{~B}$, the US part (\$47B) accounting for more than $50 \%$, with $\$ 18 \mathrm{~B}$ for NASA, $\$ 2.3 \mathrm{~B}$ for NOAA and $\$ 22.5 B$ for Department of Defence. Europe spends roughly $\$ 10 B$ every year, including $€ 2$.3B budget from the European Commission (FY 2019) and $€ 4$.3B from the European Space agency, without EU grant $(1.315 \mathrm{M} €)$ and Eumetsat contribution (221 M€). At national level, France and Germany have the most important space agency budgets, with $€ 1.47 \mathrm{~B}$ for CNES and $€ 840 \mathrm{M}$ for DLR (excluding their contributions to ESA). China's budget is estimated between $\$ 6$ and $\$ 10 \mathrm{~B}$.

\subsubsection{The rise of private investors and VCs in space}

According to a study prepared by Bryce Space and Technology [1], start-up space ventures have attracted over $\$ 21.8 \mathrm{~B}$ of investment since 2000 , including $\$ 8.4 \mathrm{~B}$ in early and late stage venture capital, $\$ 3.1 \mathrm{~B}$ in seed financing, and $\$ 4.7$ billion in debt financing (Fig. 8). More start-up space companies reported investment in 2017 and 2018 than in any other year.

More than $85 \%$ of Venture Capital investment was spent in the last four years. In 2018, 187 investors put $\$ 2.5 \mathrm{~B}$ into 82 start-up space ventures. About $51 \%$ percent of all venture investment in the last four years has gone to SpaceX and OneWeb.

The geographic breakdown of investment is unbalanced: start-ups in the US (in particular California) received 80\% of all investment in 2018, while nearly half of investors are non-US. Outside US, UK, Canada and China have the most dynamic start-up ecosystem. Bryce figures are consistent with those highlighted in a recent report of the European Investment Fund [22] reviewing all economic sectors and not only space: VC investment as a share of GDP is between $0.32 \%$ and $0.38 \%$ in the US and in Israel, while it is only about $0.025 \%$ in Europe, even if the transaction intensity is increasing since 2017. A second concern for European space start-ups is the strong focus on seed and early stage investment. With a stability of the growth capital, the lack of large Series-B and Series-C rounds is a risk for their development, hampering the emergence of European unicorns.

\subsubsection{Big revenues with services: the new El Dorado?}

Service market is the main growth opportunity for the new

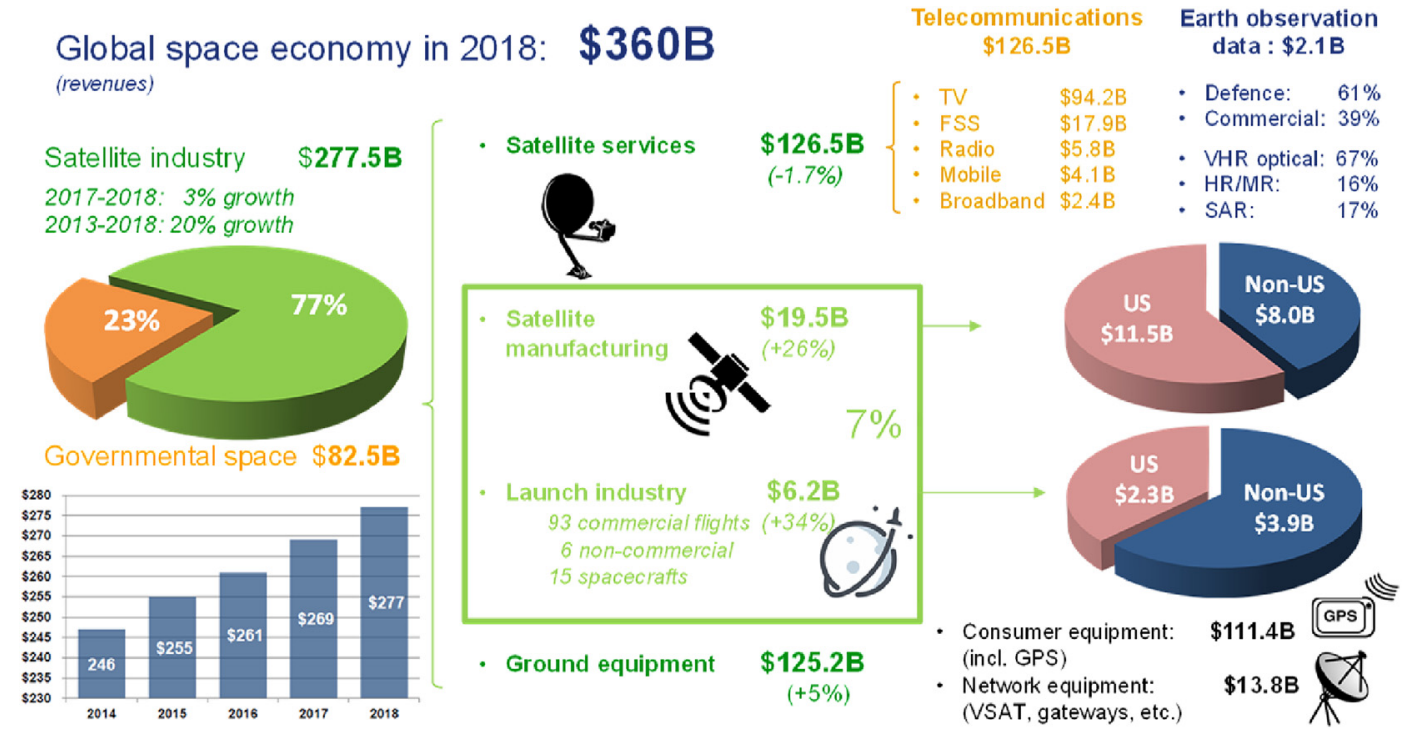

Fig. 7. Main space budgets worldwide (data sources: Bryce Space and Technology and Euroconsult). 

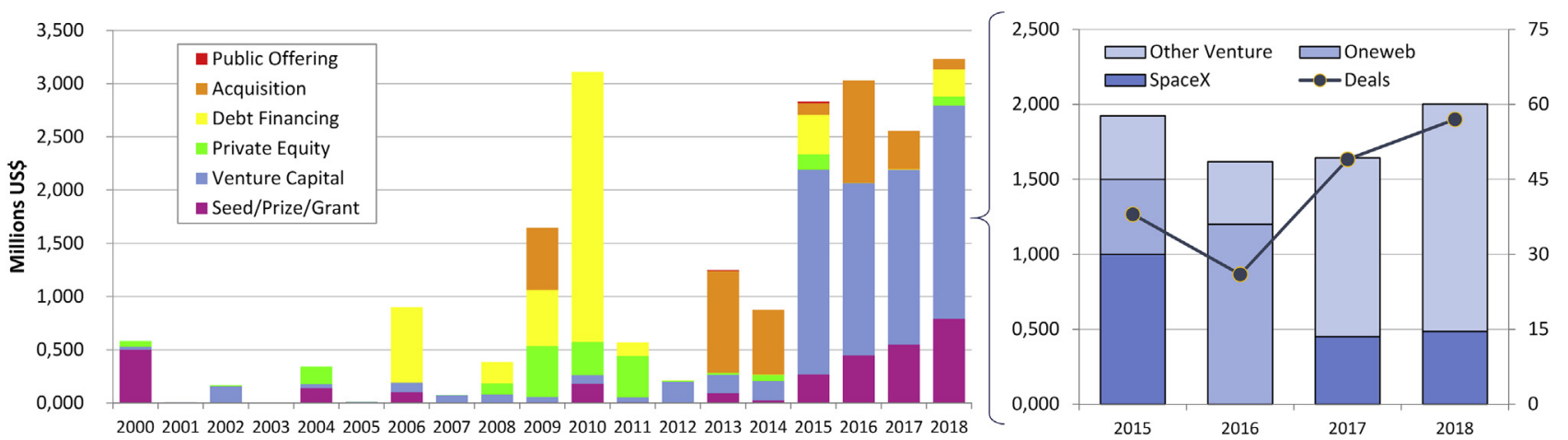

Fig. 8. Left: investment in new space, including debt, acquisitions and offering (2000-2017). Right: Venture Capital investment including SpaceX and Oneweb. Source: Bryce Space and Technology, Start-up Space 2019.

operators. The challenge is to convert promises into tangible achievements, depending on the successful implementation of the new initiatives and the growth of commercial demand. A question mark is the size of the new markets and the customer's profiles, with a transition from B2G to B2B or from B2B to B2C. The main risk is the "hype effect": new initiatives could collapse due to lack of funding or a viable business model. With five or six or more players going after the same market, will each of them be able to capture enough market shares to sustain their operations (e.g. high speed Internet from space)?

\subsubsection{Big money: low cost and new pricing schemes?}

Cost-plus pricing is the usual model for space activities: the seller calculates all costs, fixed and variable, and applies a mark-up percentage to estimate the price. The mark-up is sometimes specified by the buyer. Cost-plus pricing has many advantages (e.g. easy justification, customer trust) but this pricing model can discourage efficiency and cost optimization.

The main principle of value-based pricing is to customize prices. It sets prices according to the perceived or estimated value or benefit of a product to the customer. The approach is relevant for mass-market products and services. Value-based pricing uses retail cost as a way to send a marketing message about quality.

\section{Back to the future: possible evolutions}

\subsection{Overview}

How will evolve space activities? What can be the impacts of the new trends on the space ecosystem and the main stakeholders involved, either new or legacy players, industrial or institutional. Today, the prevailing view is that older companies, despite their know-how, cannot make the shift to the new space activities, but new start-ups can. Could it reach such an extent that these legacy organizations could soon be perceived as underdogs?

\subsection{Big space is here. It will last with a strong impact on the space ecosystem}

First medium size constellations are in operation and the next ones will be larger, triggering additional demand for launch services, ground systems, etc. The flow of money from VC investors, millionaires and private companies is healthy. More and more countries aim at becoming space-faring nations: new space agencies are created (e.g. Australia, Luxembourg). Despite concerns on a bursting bubble raised by some observers and a market take-off slower than expected, strong drivers influence space activities:

Appetite for information and connectivity is increasing with the digital transformation of society and the globalization of economy: even if the business case for the " other three billions » is questionable, an important economic activity is based in the regions of the world where « digital divide » is not a buzz word.

Science, knowledge and exploration (including human space flight) remain strong sources of inspiration. These challenging missions are a market in itself but also contribute to develop new technologies and solutions that can be applied later to commercial space activities. In the context of climate change and severe environmental concerns at global scale, new satellites and new sensors with improved performance are needed to provide useful and valuable meteorological and climate data.

Last but not least, militarization of space seems to become more and more a fact, triggering new missions: orbital services, space surveillance, etc. In this particular context, large constellation projects are generally viewed as providing a greater resiliency and redundancy for national architectures. This interest for the future mega-constellations has a positive effect on these programmes. New space solutions will deeply affect the habits of the space industry: development at lower cost and with very short delays, massive use of COTS, evolution of reliability concepts, etc. These evolutions will have a long lasting effect.

\subsection{Space is less "rocket science" than before}

Going to space and operate a satellite in orbit remains a complex task: reaching orbital speed or survive space environment is not so easy. Early failures of cubesats in orbit remind it regularly. But new facts deserve some consideration. The main impact of the popularity of cubesats is the emergence of standards and COTS components for very small satellites. Lot of entry barriers have been removed or lowered.

Furthermore, specialised companies propose now dedicated launch services or dispensers of small satellites from the ISS. They streamline and simplify the interface with the launch provider or the host client. Last but not least, many young graduate students who have already developed or even launched a cubesat, during their curriculum and before their first job in a space company. It was not the case ten years ago, even if some space agencies were already proposing hands-on activities with model rockets, stratospheric balloons or cansats [23]. These young and skilled talents have often a mindset of entrepreneur. They know that a professional experience in a start-up, even it fails, will not be a loss of time. Combining young talents and older people retired from space industry, often presented as advisers in the start-ups pitches, can be a winning option. Similar scenarios in a new spacefaring nation have a strategic impact.

\subsection{It's a long way to the top: a slow disruption?}

\subsubsection{The numbers don't lie ...}

"There is really not that much demand": market projections reported in section 4 show a continuous but slow growth of space revenues. The disruption of the market by the newcomers and the development of new 
applications seem to be at least much slower than the promises made to the investors.

\subsubsection{First tangible impacts on the supply side}

There is a risk of oversupply with an increasing number of guests around the table. Furthermore, new customers (from B2G to B2B and from $\mathrm{B} 2 \mathrm{~B}$ to $\mathrm{B} 2 \mathrm{C}$ ) are not easy to attract: the size of the pie is the big unknown. A price war would be a very risky short term strategy affecting the revenues and the cash situation of the start-ups. In similar cases, the nightmare scenario is the possible bursting of the bubble, triggered by an excessive valuation of the start-ups, not correlated to their future revenues. The risk exists but the likelihood seems low, in the words of many VC investors. Despite the small number of exits and acquisitions, investors remain confident.

In the telecommunication sector, the massive constellations are still in development or early deployment. It's too early to conclude on the value of the business case. Assessing Earth observation is more difficult with two opposite strategies: high revisit versus very high resolution. The main expectation is to unlock new markets and applications for new customers but it is not yet materialized.

Today, the key question is not "when will the bubble hustle" but "how long will it take before concrete effects on markets become visible" and "what will be the size of the cake". Some actors, young or older, will disappear, be acquired or merge with other. It explains also the "waitand-see" attitude of some the most important GEO operators.

\subsection{Space will be less stand-alone with a tighter integration with terrestrial} systems

\subsection{1. "Decompartmentalization" of space activities}

Using COTS, technologies developed outside the space sector and development methods inspired by software industry (DevOps), new space actors advocate a higher "fluidity" in the relations between the space sector and other key sectors of the new economy (electronics, 3D and additive layer manufacturing, artificial intelligence, big data) in a perspective of cost reduction, process automation and enabling access to a wide base of customers or users. In fact, it's about de-ghettoising space.

\subsubsection{The growing role of ground infrastructures}

An important dimension of the new space trends is the growing importance of the ground components in space systems. For operational missions, they play more and more a critical role. It's true for Earth observation, for end-to-end performance from tasking to image distribution. It is also critical for the massive communication constellations with a large network of gateways interconnected through terrestrial networks.

\subsubsection{Space and terrestrial solutions}

A further evolution seems realistic: the tighter integration between space and terrestrial networks (e.g. for broadband Internet or 5G backhauling in remote areas). By extension, space systems could become a small piece in a large system and be considered as commodities. A direct consequence is the evolution of roles and added value between satellites operators and generalist operators. From this perspective, the "deghettoisation" of space can have positive consequences (wider use) but also negative impacts (dissolution of space in the large ICT ecosystem).

\subsection{When small becomes bigger}

\subsubsection{From garage to factory ...}

Building an operational cubesat, even $6 \mathrm{U}$ or $12 \mathrm{U}$, is realistic for a first prototype. For this minimal viable product, the new entrepreneur can still expect to build it in "Garage mode », using the way of working used for his first nanosat. But developing and operating an operational constellation with tens or hundreds of satellites is another story. Even if well designed and modular, the complexity of these systems requires program management, project control and procedures.

\subsubsection{Convergences and differences}

The challenge for the mature start-up is to find the right organizational and managerial model without losing its agility and execution speed. On the opposite side, larger legacy players shall also adapt their model in a new competitive landscape. The well-defined and sometimes heavy processes agreed with the space agencies for the most complex and critical missions shall be tuned or even fully reshuffled. In this context, lean management and lean production tend to become the new golden rules: "reduce or remove everything which is not added value". Beyond cost reduction and increased control of the added value, schemes such as vertical integration, by removing the cascade of classical customer-supplier relationships, extend the lean objectives to the whole supply chain. The second key word is "agility". Inspired from modern software development methods (DevOps culture), the idea is to implement shorter cycles.

The question of the innovation capacity in established organizations goes beyond the scope of this study and deserves a specific paper: the lessons learnt from a voluntarist innovation policy launched since 2012 at Airbus (open innovation, internal call for ideas, corporate venture fund, protospace or bizlabs initiatives) show tangible results and benefits.

\subsubsection{Towards larger series and mass production}

The raising interest for constellations accelerate the transformation of the production: the larger series of satellites, even if their size is still modest compared to cars and aircrafts makers, call for new manufacturing processes and new paradigms for tests and qualification. All incumbent actors and their supply chain experience this adaptation. Those already involved in commercial markets and on competitive export markets or operating their own infrastructure through service offers are better prepared to achieve this deep transformation compared to other companies still focuses on defence and institutional markets [23]. There is eventually some convergence between the start-ups and the usual suspects. A typical example is the involvement of large European primes such as Airbus and Thales Alenia Space in the new constellations (Iridium Next, Blacksky Global, OneWeb, Telesat). It confirms that these companies are considered as credible and competitive suppliers. This situation is a major asset for Europe.

\subsection{New applications, market growth and new competitors, the supply chain will be shaken in the coming years}

\subsubsection{Ecosystem evolution}

"Natural selection" in Darwin's theory [25] or "survival of the fittest" for Herbert Spencer [26] refers to organism's ability to adapt to changes in its environment and adjust accordingly over time. The general concept has been taken up by marketing and management theoreticians [27]: "It is not the strongest of the species that survives, nor the most intelligent that survives. It is the one that is most adaptable to change". Keeping in mind the limits of this analogy, current trends in space activities allow foreseeing possible scenarios in the short or medium term. Following evolutions appear plausible, depending on market growth and success of new products. It highlights a much more complex landscape than the one usually reported about New Space.

\subsubsection{New companies, business models and markets}

A small number of new unicorns: a start-up company becomes unicorn when its value is over $\$ 1$ billion. There are only few involved in space activities: SpaceX, Blue Origin, Rocket Lab, Planet, OneWeb. High valuation does not mean large revenues. But, under high market uncertainty conditions, if one assumes that venture capitalists are "informed agents" [28] able to identify start-ups that will achieve future 

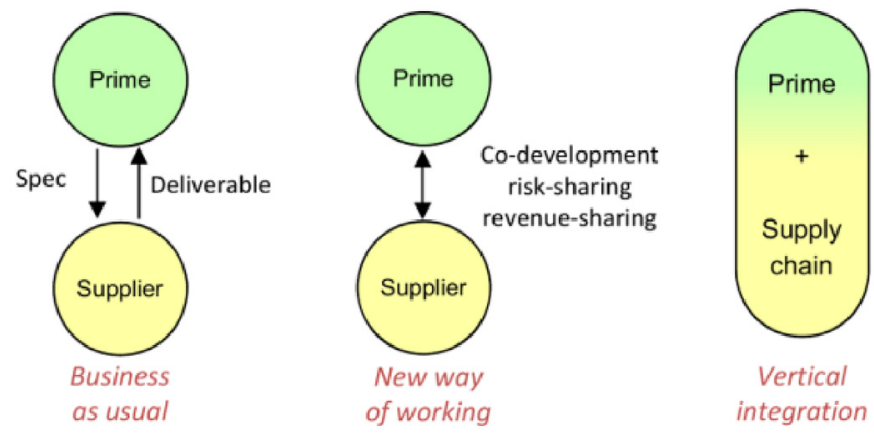

Fig. 9. New types of relations in the supply chain.

success on the market, valuation can be seen as a good indicator of market potential.

A new game of Thrones: how many winners? On the global markets (e.g. massive constellations for high speed Internet), the downside effect is a situation "winner takes all": only one, two or three champions will survive, with an incentive for the first ones on the market. Despite the high number of seed/Series A rounds in Europe, it could also mean that VCs will become henceforth much more selective. The new markets will also affect the legacy ones. For instance, assuming the low level of orders for heavy satellites and considering that the downturn is not cyclical, SSL decided to downsize its large Geosynchronous Earth Orbit (GEO) operations and refocus on activities for US government, LEO communications and Earth observation markets.

The golden egg: new services. For start-ups and investors, the holy grail seems to be the provision of global services (communications, Earth observation, M2M and IOT) sold to a large number of users. New players can position themselves on this segment. For most of the satellite manufacturers, it means a drastic change of paradigm, with the underlying risk to compete with their own usual customers. Airbus Defence and Space is an interesting example: compared to its US competitors, Airbus is already active as service provider in Earth observation and military communications but acts as a pure manufacturer in commercial communications.

Disruption in the supply chain: albeit the dominant idea in new space is vertical integration, an increasing number of companies propose the externalisation of non-core business tasks. A typical example is the amount of start-ups proposing GSaaS (Ground Segment as a services) with virtual networks of ground stations. There is also a great potential for a new generation of suppliers providing components and subsystems for space missions: platforms, sensors, electric propulsion engines, laser communication terminals, etc. It can include start-ups develop innovative solutions or legacy suppliers adapting their own company model to low cost and mass production. A very positive effect in a given nation can be the reduction of dependence on other nations for critical technologies. Beyond the profusion of start-ups blossoming everywhere, a key question is "how many suppliers is enough in order to ensure non-dependence and competitiveness?"

\subsubsection{External growth, mergers and acquisitions or strategic partnerships}

Merger and acquisition or strategic partnership deals aim at increasing revenues and market share or mitigating competition. All scenarios seem realistic and are already happening:

Start-ups acquire other start-ups or team together: a typical example is the acquisition of Terra Bella by Planet in April 2017. Another example is the acquisition of Clyde Space by AAC Microtec. Merger and Acquisitions activities led by start-ups will likely intensify and might become a priority for the new space industry.

Start-ups acquire older companies: the large volume of VC investment enables these amazing decisions. Planet is also a good example, with the acquisition of BlackBridge and its RapidEye constellation of satellites in July 2015. A second example is the acquisition of Deimos Imaging by Urthecast.

Big companies acquire or partner with promising start-ups: the rationale is often the quick extension of the existing portfolio (small satellite platforms, service provision, access to new markets) and agility improvement. It has also impact on competition. Many acquisitions or partnership agreements occurred recently: in August 2018, Boeing acquired Millennium Space Systems, a provider of small-satellite solutions. In September 2018, Airbus Defence and Space has entered into a partnership with Orbital Insight, a pure data analytics company.

\subsubsection{New positions in the value chain}

The most ambitious start-ups want to disrupt or shift the value chain and sit at the top of pyramid, with a direct interface with the final customer. The customer becomes a consumer, with less influence on the specification of the products. The preferred schemes (Fig. 9) are the provision of end-to-end services at global scale (e.g. broadband communications) and the vertical integration (e.g. from EO satellites manufacturing to data analytics). Service development is the main driver, even if the market perspectives are still uncertain. Traditional companies adapt and take new approaches. There are interesting opportunities.

In this landscape, the legacy satellite manufacturers seem in a good position to become suppliers of new operators. These operators choose companies with recognised know-how and experience (e.g. Thales Alenia Space and Blacksky Global or Airbus Defence and Space and Oneweb). In many cases, the pure customer-supplier relation disappears, as the manufacturers provide also some investment. The evolution of the relationship from standard procurement contracts to strategic partnership agreements applies throughout the supply chain. If space systems are further integrated in global information systems, they can become a commodity with a less central role for the space primes.

5.7.5. New spacefaring nations and the emergence of a domestic industry

The direct consequence is a drop in export activity for the former suppliers. A typical example is the Chinese case with a drastic reduction of EO data imported by China, since 2013. China operates high and very high resolution satellites and was the first on the orbital launches podium in 2018. China will become more and more a competitive player on the worldwide satellite market. China exhibits a vibrant startups landscape. India has similar ambitions.

\subsection{The mission of space agencies and institutional actors will change}

\subsubsection{Disruption ahead}

Space agencies face a potential disruption that is at least as important as for industry, raising questions on their role and "raison d'être". Space agencies in the historic spacefaring nations have to adapt to a new context with more commercial activities, a growing role of private investors and a mature industry.

In this context, as depicted on Fig. 10, the role of space agencies will change a lot, implying new forms of relation with industry and private sector (Public Private Partnership, co-development).

Agencies will have to redefine their core missions: competitiveness

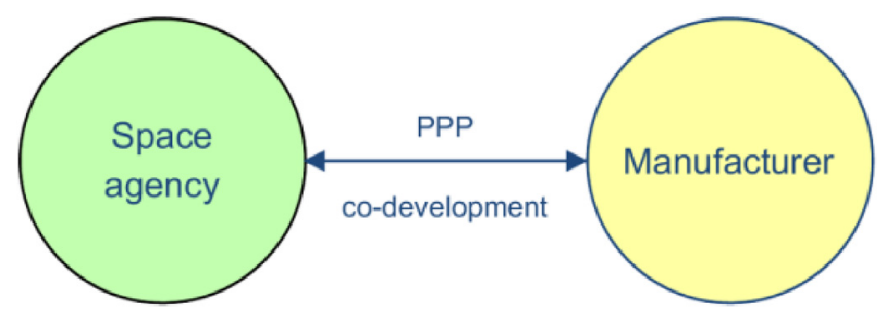

Fig. 10. New relations between agencies and industry. 
of national space industry, preparedness for the future, R\&T and innovation, public and non-profit activities (science, exploration), "inspire and make dream", long term objectives and a stronger segmentation between policy role and technical activities.

\subsubsection{From successful trials to new models}

Some innovative models have already been implemented, such as ESA ARTES program or partnerships between CNES and industry in the context of France NFI (New Industrial Policy). It's more difficult for sovereignty missions that have been historically defined and led by the space or defence agencies. Earth observation is a typical example: performance of commercial very high resolution satellites is increasing with a high degree of convergence with the defence needs. Deciding who shall be in the driver's seat is not obvious. Even when there is a willingness to partner, the rules of the public contracts or the use of competitive procedures can be showstoppers.

Between tailor-made (customer specifies) and ready-to-wear (less influence of customer on specification), innovative contractual schemes imply an evolution from procurement of proprietary and legacy systems to service contracts. For the suppliers, it can mean a profound adaptation or even revolution from satellites manufacturing to service provision.

Lessons learnt in the US confirm the critical role of the public sector and highlight some good practices. Even if they can't be directly applied in the European context, they can engender news types of relations between industry and the national or European institutions: requirements driven by mission performance instead of technical specification, risk-sharing schemes, service level agreements, dual use missions, etc.

\subsubsection{New networks and dependencies}

For institutional and defence users, it could mean an increased dependence, direct or indirect, on uncontrolled networks. Governmental and institutional actors usually prefer to own their own capacities: for them, purchasing external services or using systems that they have not fully specified means a real change of paradigm. Last but not list, anchor tenancies and framework service contracts challenge the usual budget planning model, require flexibility and decision speed. Accepting and implementing this evolution of the missions is not easy for the main space agencies, as it affects their basic mandate, their DNA and their structure with possible impacts at social level.

\subsection{An increasing weight of commercial activities but direct and tight links with national policies}

\subsubsection{A new space race, 50 years after Apollo 11}

2018 was a record year in terms of orbital launchers with 114 orbital launch attempts. The two leading nations, USA and China, have ambitious plans and the capacity to implement them with, in both cases, a powerful mixture of governmental policies and private space ventures. Prestige, dominance but also economy are at stake in this new space race. Access to space is always considered as a key element of sovereignty and autonomy but a larger number of satellites is commercial. Nevertheless, it confirms the strong dependency between national policies and commercial activities, as recently demonstrated by Vice-President Mike Pence during his inaugural speech at IAC 2019, reiterating Donald Trump's vision for the United States to lead in space once again and highlighting the role of provate entreprise in space exploration.

\subsubsection{The role of Europe beside the two champions}

With an increasing US and Chinese dominance in space, there is a risk of dropping out for the other spacefaring nations, with impacts not only on national prestige and sovereignty but also on industrial competitiveness. If they want to stay in the race, these nations have to define new strategies to cope with the worldwide champions. Can it be achieved at national level in Europe? National sovereignty is obviously an important parameter but is it the right answer when one takes into account other drivers such as population or national Gross Domestic Production?

This lack of level playing field between the US and Europe [11] is the main challenge and goes far beyond the pure space policies and the breakdown of responsibilities between national and European levels. Even if it starts later than in the US, the need to foster innovation and start-ups is now acknowledged. Supporting the industrial champions (primes and providers of critical components) in the worldwide competition and develop world-class service providers is also critical and seems less understood.

At least three reasons explain this situation: first, the US case where a part of the large industrial players, backed by the size of the defence markets, have been sometimes less agile and less forced to adapt their model, the perception that the economic growth and the jobs creation will mainly be driven by small companies (despite a high failure rate) and, last but not least, the idea that large primes are powerful and don't need a strong external support (sometimes confirmed by their successes (export markets, massive constellations).

\subsubsection{One size will not fit all ...}

Space environments in Europe, in the US or in China are not so comparable. Each policy shall depend on the local context. For instance, building a commercial downstream activity on the basis of a "free and open" access to the data remains a challenge: the lack of a large, structured ICT sector, comparable to the existing majors in the USA, as well as the small size of institutional or defense markets are two weaknesses hampering a quick rise of the space sector in Europe.

\subsubsection{Towards a global governance}

Big investments, big systems, new operators, a new dialogue between companies and institutions and nations, new missions and finally a new space economy, these trends are calling for a new governance model. Current policy conditions have not led to high-level agreements between the main spacefaring nations. However, as the number of satellites in orbit increases and new forms of activities in space emerge, global governance ideas will probably gain a new momentum.

\section{Conclusion}

Something big is happening in space. Even if it is too early to depict the new landscape, this study shows that the future picture will not be black and white but much more colourful. Nuances will depend on markets, regional specificities and national policies. Instead of one the six extreme scenarios depicted in section 3, one can anticipate a hybrid situation with growth opportunities, "small and local dotcom-like bubbles" for some very new and highly disruptive markets and a redistribution of the value chain and market shares. The tight dependencies in this changing ecosystem can trigger snow-ball effects. In any case, it will not be "back to business as usual".

The popular expression "David versus Goliath" refers to a competition where a weaker opponent faces a much bigger, stronger adversary. In the new space race, who is the new David? Can Goliath sometimes win? With new space becoming big space, the difference between large companies and mature start-ups fades: the size and the age of the company are less important than its agility, its mindset, its ability to manage risks in complex projects and to cooperate with other commercial and institutional actors.

\subsection{Convergences and differences}

One collateral but significant effect of SpaceX success is the wake-up call for space industry. All major companies carefully monitor the creation of new space ventures. But it would also be a mistake to think that space start-ups is the only concrete expression of the big space era.

While the disruption of space champions is still a hypothesis, with 
market growth obviously slower than promised by many start-ups, new space has already a lot of impact on the space ecosystem.

\subsection{The reinvention of space industry}

A large evolution of the industrial landscape is expected in the coming years with new unicorns and new suppliers, turmoil in the value chain, new services, mergers and acquisitions, etc. In the short term, the most likely scenario is an intensification of mergers and acquisitions between start-ups and between start-ups and legacy actors. Furthermore, if the huge development of new services based on space assets becomes a reality, the link with terrestrial systems will be reinforced, with impact on the positions and weights in the value chain. This "de-compartmentalization" of space means opportunities and threats.

The closer link between space activities and information and communication technologies (e.g. data analytics, big data, cloud computing and artificial intelligence) is also raising new strategic issues on the critical technologies and capacities. Access to space is always considered as a key condition of autonomy. It is obviously true but what would mean an independent capacity to put satellites into orbit if the exploitation of data delivered by those satellites relied exclusively of ICT solutions provided by US or Chinese companies?

\subsection{Impacts on national policies a new "raison d'être" for space agencies?}

The role of space agencies will also evolve, with new types relations with industry and open questions on the core missions. This evolution can be disruptive. Despite the growing weight of commercial activities, New space means strong links with national policies: development of local space industry, space laws, space police or even militarization of space.

\subsection{New ambitions and new visions}

The USA and China have ambitious plans and the capacity to implement them, with a powerful mixture of governmental policies and private space ventures. A new space race has started between the two leading space faring nations. Prestige and dominance are at stake but also economy. Europe, India, Russia, Japan, Israel? Which nation will be the third on the podium? Is it achievable in Europe at national level? The main question is the breakdown of responsibilities between national and European levels and the complexity of the governance.

Beyond the evolution of business activities, a key question is: "What do we want to do in space?"

What is the ultimate goal? Protection, exploitation or exploration? In 2016, Elon Musk proposed his own vision with a settlement on Mars [29]. His vision ("Making Humans a Multi-Planetary Species") can be challenged but he filled a gap left empty since the end of the cold war. Who has the legitimacy to propose a vision of space activities?

Are nations and agencies still able to propose a vision or challenge those proposed by the Silicon Valley entrepreneurs? For Thomas Edison, Vision without execution is hallucination". What is execution without vision?

\section{References}

[1] Start-Up Space, Update on Investment in Commercial Space Ventures, Bryce Space and Technology, 2019 (accessed May 2019), https://brycetech.com/downloads/ Bryce Start Up Space 2019.pdf.

[2] Northern Sky Research, The Emerging Space Market Opportunity Northern Sky Research, Northern Sky Research, September 2017 (accessed Sept. 2018), https:// www.nsr.com/research/the-emerging-space-market-opportunity/.

[3] OECD, The Space Economy at a Glance 2014, OECD Publishing, 2014 N 978-92-6421729-4.

[4] Space Frontier Foundation web site, https://spacefrontier.org/what-is-newspace/.

[5] Martin Sweeting, Modern small satellites - changing the economics of space, Proceedings of the IEEE, vol. 106, 2018, pp. 343-361, , https://doi.org/10.1109/ JPROC.2018.2806218.

[6] Michael Lewis, The New New Thing: A Silicon Valley Story, (1999).

[7] Peter Lothian Nelson, Walter E. Block, Space Capitalism: How Humans Will Colonize Planets, Moons, and Asteroids, Palgrave Macmillan, 2018.

[8] J.-M. Dru, Disruption : briser les conventions et redessiner le marché, Pearson France editions, Feb. 1997.

[9] Clayton Christensen, The Innovator's Dilemma: When New Technologies Cause Great Firms to Fail, Harvard Business Review Press, 1997.

[10] Global space industry: refining the definition of newspace, Jason Hay, Paul Guthrie, Carie Mullins, Elaine Gresham, and Carissa Christensen (The Tauri Group), AIAA SPACE 2009 Conference \& Exposition, https://doi.org/10.2514/6.2009-6400.

[11] The challenge of future space systems and services in Europe, Gil Denis, Xavier Pasco and Hélène Huby, Défence et industrie, $n^{\circ} 4$, june 2015, edited by Fondation pour la Recherche Stratégique, https://www.frstrategie.org/publications/defenseet-industries/web/documents/2015/4.pdf (accessed Sept. 2018).

[12] The definition of ecology, Dictionary.com. https://www.dictionary.com/browse/ ecology. Accessed Sept. 2018.

[13] Richard G. Harrison, Erica L. Larson, Hybridization, introgression and the nature of species Boundaries, J. Hered. 105 (S1) (Jan. 2014) 795-809, https://doi.org/10. 1093/jhered/esu033 Accessed Sept. 2018.

[14] To Infinity and beyond - Global Space Primer, Bank of America Merril Lynch, Thematic Research, Oct. 2017 Accessed Sept. 2018 https://go.guidants.com/q/db/ a2/1e1ffc185c1d44bd.pdf.

[15] Global Sensors in Internet of Things (IoT) Devices Market, Analysis \& Forecast: 2016 to 2022, Research and Markets, February 2017 accessed Sept. 2018) https:// www.researchandmarkets.com/research/bvgxvl/global_sensors_in.

[16] Treaty on Principles Governing the Activities of States in the Exploration and Use of Outer Space, Including the Moon and Other Celestial Bodies, (1966) (Accessed Sept. 2018), http://www.unoosa.org/oosa/en/ourwork/spacelaw/treaties/ introouterspacetreaty.html.

[17] Frans von der Dunk, Fundamental Provisions for National Space Laws, University of Nebraska - Lincoln, 2006, http://digitalcommons.unl.edu/spacelaw/11.

[18] Understanding business model disruption in the mobility industry, Olaf Sakkers, Maniv, https://medium.com/maniv-mobility/understanding-business-modeldisruption-in-the-mobility-industry-980fa276b70e (accessed September 2018).

[19] Gil Denis, Alain Claverie, Xavier Pasco, Darnis Jean-Pierre, Benoît de Maupeou, Murielle Lafaye, Eric Morel, Towards disruptions in Earth observation? New Earth Observation systems and markets evolution: Possible scenarios and impacts, Acta Astronaut. 137 (2017), https://doi.org/10.1016/j.actaastro.2017.04.034.

[20] Morgan Stanley Research, Investment Implications of the Final Frontier, Morgan Stanley Research, October 2017.

[21] Bryce Space and Technology, $21^{\text {st }}$ Annual State of the Satellite Industry Report, prepared by Bryce Space and Technology for Satellite Industry Association, May 2019, 2019 (Access May 2019), https://www.sia.org/2019_ssir/2019.

[22] Helmut Kraemer-Eis, Frank Lang, Wouter Torfs, Salome Gvetadze, European Small Business Finance Outlook, Report of the European Investment Fund (2017) Working paper 2017/43 https://www.eif.org/news_centre/publications/eif_wp_43.pdf (Access May 2019).

[23] Christophe Scicluna, Jean-Claude Guiraudon, Pierre Quetard, Pignolet Guy, Préaux Guy, Michel Maignan, Gil Denis, Marc Zirnheld, Eric Couffin, Samüël Kauffman, Paula Bruzzone, 50 Years of Space Education and Outreach in France with Planète Sciences and CNES, IAC, 2012.

[25] On the Origin of Species by Means of Natural Selection, or the Preservation of Favoured Races in the Struggle for Life, Darwin, 1859.

[26] Principles of Biology, Herbert Spencer, 1864.

[27] Leon C. Megginson, Lessons from Europe for American Business, Southwestern Social Science Quarterly, 1963.

[28] Venture capitalist certification in initial public offerings, in: W.L. Megginson, K.A. Weiss (Eds.), J. Financ. 46 (1991) 879-903.

[29] E. Musk, Making humans a multi-planetary species, New Space 5 (2) (Jun. 2017), https://doi.org/10.1089/space.2017.29009.emu. 